\title{
Yin-Yang, Mind, and Heart-Mind
}

This chapter and the two to follow focus mainly on philosophical issues about East and West-where East is narrowly understood to mean East Asia and, in some instances as context will indicate, simply China. I think comparisons between East and West can help us in contemporary terms with our general understanding of a number of important philosophical questions. In these early chapters I shall be raising some issues of or about psychology that I believe profoundly affect what it makes most sense for us to say or conclude as philosophers East or West, and this emphasis on psychology will be all the more apparent when in later chapters we move beyond explicitly East-West themes and speak about how psychological issues that haven't previously been explored can and should affect what we want to say about ethics: most specifically about the age-old problem of justifying justice or moral virtue. But I want to begin the present chapter by homing in on a distinction, the distinction between what Westerners call mind and what Easterners call heart-mind.

\section{1}

Kant gave us a transcendental argument that sought to show that space, time, causality, and enduring physical objects are necessary conditions of the unity of consciousness. He also thought consciousness was or could be pure: that is, he saw the mind in the typical Western philosophical fashion as capable of pure reason unalloyed with emotion. But in the Far East our

(C) The Author(s) 2020

M. Slote, Between Psychology and Philosophy,

Palgrave Studies in Comparative East-West Philosophy, https://doi.org/10.1007/978-3-030-22503-2_2 
human psychology isn't thought of in this way. It is assumed that reason(ing) and emotion cannot fundamentally be separated, and the terms xin in Chinese, maum in Korean, and kokoro in Japanese all reflect the latter assumption: that is why it has seemed so natural to translate all these terms into English as "heart-mind," not "mind." The latter word connotes at the very least the possibility of purely rational and nonemotional psychological functioning, and that is what Eastern thought typically doesn't subscribe to.

If we can show that pure reason isn't possible and that "xin" and so on characterize our psychology better than "mind" does, then a major part of Kant's enterprise is undercut and/or seems beside the point. But we may be able to learn something valuable from Kant's method of proceeding even if not from the assumptions he made in proceeding as he did. In this chapter I want first to try to vindicate xin, and so on, over mind, but having done that, I want to offer a kind of transcendental argument vis-à-vis the heart-mind (rather than the mind). I hope to show you that yin-yang is a necessary precondition or presupposition of the heart-mind: more specifically, that the functioning heart-mind necessarily has a yin-yang structure. All this is a tall order to be taking on in one chapter, but it is worth pursuing this line of thought, however incompletely it will be represented here, for at least two reasons. ${ }^{1}$ First, what I shall be proposing and arguing for treats Eastern thought as relevant to the field called philosophy of mind in a way that will be surprising to Western philosophers and may even be surprising to Asian ones. From the standpoint of philosophy as it is pursued overall in today's increasingly internationalized world, it will be important if it turns out that the philosophy of mind has to draw on Eastern notions like heart-mind in order to make contemporary progress. Second, if we can show that our psychology is best understood in terms of a heart-mind and if we can then show that heart-mind has to be understood in yin-yang terms, then a second Asian and in this case specifically Chinese concept will have been shown to be helpful and perhaps even essential to making progress in the philosophy of mind. Western

${ }^{1}$ I offer a more complete argument in my The Philosophy of Yin and Yang (Beijing: the Commercial Press, 2018, with side-by-side English language and Chinese language texts). But by incompleteness I don't mean that I am expecting the readers of this chapter to take anything on faith, anything that cannot be seen as plausible in the absence of further argumentation. The point, rather, is that the book just mentioned offers a more foundational and unifying account of the relevance of yin and yang to philosophical issues, and the discussion here seeks to deal plausibly and on its own with only one aspect of yin and yang. 
philosophers will have all the more reason to pay attention to Asian thought, and even if they resist doing that, Asian philosophers will be able to make use of their own endogenous concepts/ideas to further enrich their own traditions and take their own philosophies into the future.

I can tell you one probable reason why no one up till now has ever argued with any specificity that yin-yang is the necessary basis for the heartmind. No one has done this because yin and yang are or were traditionally regarded as mainly physical properties, like cold vs. warm, female vs. male, dark vs. light, and wet vs. dry. Such properties were used to give protophysical explanations of natural phenomena (on a par perhaps with the kinds of physical/biological explanations the ancient Greeks went in for), and of course even today such thinking has its place in Chinese medicine, feng shui, and macrobiotic dietetics. Many intellectuals in East Asia are suspicious of these applications of yin-yang, and that, together with the mainly physical notions associated historically with yin and yang, has, I think, led philosophers with East Asian roots or citizenship to underestimate the potential of yin and yang. (Of course, Western philosophers would normally see nothing of philosophical interest in yin and yang, either.)

Now don't ask me how this particular Western philosopher came to see yin and yang as philosophically important and as undergirding the correct picture of our psychology as embodied in words like "xin," "kokoro," and "maum." I could tell you, but it would take time away from my main argument. So let me proceed with the philosophy and omit the autobiography (except in a later footnote). I will begin by saying something about maum, and so on, seen as heart-mind. I will argue that heart-mind is a much better way of representing the basis of human psychology than mind is. Then I will show you how an updated notion of yin-yang, one that picks up on certain historical aspects of yin-yang but that also reveals what I think has been deeply buried or impacted within traditional Chinese or Eastern thought about yin and yang, waiting to be brought out by someone, can explain how our psychology can be and necessarily is a heart-mind psychology rather than a (pure) mind psychology.

I say that the West has seen the mind in an overly pure way, but one might object that the West allows emotion into the mind just as the East does. However, there is a difference. For the West, minds can contain emotions but needn't. And this means that our minds are not heart-minds, for the 
idea of a heart-mind clearly connotes or at least suggests that mind and emotion cannot be separated in the way the West supposes. With the exception of certain German Romantics (e.g., Johann Herder and Max Scheler), Western philosophers suppose that the mind or a mind can function on a purely intellectual basis, with inferences, proofs, intuitions, criticisms, and reasoning - whether valid or invalid - all potentially occurring in the absence of any emotion. This is precisely what talk of kokoro, and so on, doesn't suppose or presuppose. So I want to show you why I think the Western ideas are mistaken on these points about our human or any psychology. (Even the moral sentimentalist David Hume regarded reasoning and cognition as metaphysically independent of all emotion, and so I shall be arguing for a kind of cognitive sentimentalism that moral sentimentalism as such isn't committed to.)

From the standpoint of Western analytic philosophy, there are two basic contents or building blocks of the mind: desire and belief. Certain other contents of the mind (e.g., dreams, idle imaginings, drug-induced hallucinations, obsessive thoughts, and mood states like depression and mania) are naturally thought of as irrelevant to the mind as a functioning entity. But those psychological states or operations that we regard as functional all involve desire or belief or both. Thus plans and intentions cannot exist in the absence of desires, but they also necessarily rest on beliefs, and I think we can also say that intellectual operations like reasoning, intuition, and criticism all presuppose the existence of beliefs. So if I can show you that desire and belief both require emotion, the idea that a mind can in principle function without emotion and on a strictly rational or intellectual basis will be shown to be mistaken, and this will then vindicate maum, kokoro, and xin as more realistic ways of seeing and referring to the human psyche. Let me talk about belief first, because that is the hardest nut to crack. How can belief involve emotion? Isn't it purely cognitive?

Well, these are questions I would expect more from Western philosophers than from philosophers with intellectual roots in Eastern thought. The Taiwanese philosopher Hsin-wen Lee once told me how surprised she was when she first heard that Western thinkers think of beliefs as purely cognitive and free of all emotion elements; and the Japanese philosopher Seisuke Hayakawa once told me that when Japanese philosophers first started to translate works by analytic philosophers into Japanese, they had to invent a new word to translate the English word "belief" in order to do justice to the deep Western assumption that belief is purely cognitive and emotionally inert. The Japanese word that had been previously used to 
translate "belief" from English simply had too much connotation of something more than inert and intellectual. So I think that Asian scholars won't perhaps press me with the above two questions: How can belief involve emotion? Isn't it purely cognitive? However, Western analytic philosophers will or would press these questions, and (perhaps because I am Western myself) I would like to be able to answer the West in its own terms. That is, I want to offer arguments that will or ought to convince Western thinkers that they are mistaken to think that (their concept of) belief can be walled off from emotion or affect.

What are those arguments? Well, let me give them as succinctly as I can. First, there are linguistic facts that seem to have been totally ignored. When you believe a given hypothesis, you favor it over alternatives, and the same is true of any proposition one believes to be true. One epistemically favors that proposition, or, equivalently, the idea that it is true, over alternatives that have been proposed or that are or can be salient in some other way. We should take this language of favoring seriously, and taken literally, that language implies an emotion, just as when we say of someone that they favor one nephew over another or one political party over another. Why hold that talk of favoring is figurative in the case of hypotheses, assumptions, and so on, but literal in the case of nephews and political parties? We know that people are capable of having emotions vis-à-vis abstract entities: think not just of Plato's attitude toward the Form of the Good, but also of the way we quite naturally say we dislike a certain theory or approach. We are higher beings, and part of that involves a capacity for emotion directed at things other than our immediate surroundings or things we experience via the senses.

Having said this, I think we need to be clear about a distinction. In stating that someone epistemically favors a certain hypothesis or proposition (for inclusion in their overall theoretical picture of the world), we are not claiming that they are happy about its being true. For example, John was not and is still not in favor of his wife's being unfaithful to him, but nevertheless, at a certain point, he may epistemically favor the hypothesis that she has been and on that basis file for a legal separation from her.

There are other linguistic indications that belief in the ordinary sense and in general involves emotion. Why otherwise would we so naturally talk and think about defending our beliefs against objections or doubtsas if we regarded them as precious property to be guarded against devaluation or destruction? (On this last point, I am indebted to Hayakawa.) And then there is the relation between belief and confidence. When we say 
we believe something we don't automatically commit ourselves to being confident in what we believe: I often believe weather reports but I don't think I am usually confident that they will turn out to be true. (My Random House dictionary describes confidence as a state of "strong belief.") So belief seems to require only a lesser degree of confidence than actual, positive confidence itself does, and in putting belief in with confidence on a single scale in this way, don't we imply that belief involves an epistemic emotion if confidence does? Now everyone holds that confidence (like the even stronger notion of certitude) is an epistemic emotion or feeling, so why not hold the same about belief, treating it as merely involving a less strong (positive) epistemic emotion toward some idea or proposition? ${ }^{2}$

Let me mention two more points that bring in issues in philosophy of mind. One indicator that belief involves emotion is the way even trivial beliefs can be the subject of strong emotion. I don't have much at stake in believing that the Empire State Building is in New York City, but if someone were suddenly to deny that it is, arguing seriously, for example, that New York is the Empire State, so that of course the Empire State Building has to be in Albany, the capital of the Empire State, I think I would be annoyed and/or upset. I think we are emotionally involved in our beliefs, and I think that is the simplest explanation of why the peremptory denial of what we believe arouses such emotional reactions in us.

What also indicates that belief is more than or different from an inert purely cognitive/intellectual state in relation to various propositions is a fact about means-end thinking and action. If I am hungry and want food, but discover there is no food in the house, then (assuming I can't order in) that will lead me, other things being equal, to leave the house in search of food or a food store. But if the belief that there is no food at home is inert and purely intellectual, why shouldn't it just lie in the mind, once acquired, without leading to any action, for example, of leaving the house? Yet this doesn't happen. There is something about the belief there is no food in the

\footnotetext{
${ }^{2}$ But if all belief is emotional or involves emotion, then emotion will exist at every level of human epistemic de dicto rationality, and that goes against the standard Western assumption that emotions can be justified and rational only if they are based in or on epistemic states (like belief) that are entirely free of emotion. However, if one considers confidence, one can see that this widespread assumption is mistaken. Confidence is an epistemic emotion, and one can be rationally confident that one is seeing a chair without that confidence being based on some other de dicto epistemic state (and what would it be?) that is emotion-free and rational. If this works for confidence, why not for the less epistemically strong state of belief?
} 
house that causes it to engage with the desire for food, and that something has to be a factor or fact that is not strictly intellectual or inert. We can explain the fact of action in our food case if we suppose that the belief that there is no food in the house isn't just a theoretical entity, but has an emotional side to it. If believing that there is no food there involves favoring the proposition that there is no food there both for theoretical and for practical purposes, then that would help explain why the belief doesn't just lie in our minds inert when the desire for food arises within us, but is applied to that desire in the form of instrumental reasoning and action.

I hope you will join me, then, in believing that belief generally requires some kind of epistemic emotion. So the next question concerns whether desire, the other basic element of our functional minds or psyches, also entails emotion. Well, if I want to be a member of a certain club, I will have a disposition to be disappointed if I am not accepted as a member and happy, even elated, if I am. These are emotions and that means that in such a case desire entails emotion conceived as a disposition to have occurrent emotions. That is the only sense in which I think desire or, for that matter, belief involves emotion, the dispositional sense. But one might question whether every desire involves such an emotional disposition.

Consider mere preferences. I prefer coconut ice cream over cappuccino ice cream, but they are both favorites of mine, and if a given store has only cappuccino I won't be disappointed because I couldn't get coconut, the way I very much might be if I couldn't get either flavor. So isn't this a kind of desire that doesn't involve emotion? Well, I think the word "desire" is probably too strong here. That is why I spoke a moment ago of mere preferences. A mere preference doesn't give rise to disappointment or elation the way desires do. But this then raises another issue. If mere preferences don't involve emotion(al dispositions), can I say that every basic element of the or a functioning mind involves emotion?

I think I can. I don't think mere preferences should be considered part of the functioning mind because they don't give rise to plans or even intentions. My own autobiographical phenomenology tells me that I never plan or intend to get coconut ice cream rather than cappuccino, even though I am at some level aware that I will always choose the coconut if both are available. To that extent, mere preference, like mere wishes, doesn't engage with the rest of the mind's cognitive apparatus the way desires do. So I think it makes sense to conceive it as not being part of the functioning mind, and that means that the two basic elements of any possible functioning mind both involve emotion/emotional dispositions. This goes directly 
against the Western idea that the mind can exist and function in purely intellectual, rational, or cognitive terms, without any emotion(al disposition) having to be involved. So it shows that the Western conception of the human psyche and the very term "mind" itself, with its intellectualistic connotations, involve a mistaken view of what we human beings are all about. We need terms like "maum," "kokoro," and "xin" to convey what is essential to the mind, any mind: namely, that cognitive operations cannot be separated from emotion and that emotion is pervasive of any functioning mind. Thus the so-called mind is most accurately conceived as a heartmind. ${ }^{3}$ And we can also put the point by saying that the term "mind" is essentially misleading: there literally cannot be such a thing as a mind as the West has standardly conceived it. But now we have to see how and why any functioning heart-mind necessarily involves yin and yang.

\section{3}

The argument for the yin-yang basis of maum, xin, or kokoro rests on two ideas. First, and as we have already shown, on the idea that our psychological functioning necessarily and pervasively involves emotion(s) and so is necessarily a heart-mind and not a (potentially pure) mind. Second, we

\footnotetext{
${ }^{3}$ I have never heard of any Chinese philosopher's explicitly defending the intrinsic connection between the cognitive and the emotional that I have been very explicitly defending here. Perhaps that is because from a Chinese standpoint that connection seems so natural as to need no defense, but then one has to ask why Chinese thinkers haven't (I believe) made any sort of explicit case against the standard Western way of viewing the mind or against the idea of pure reason. I fear that the reason may have to do with the deference Chinese thinkers have (needlessly) displayed toward ideas from the West. It is natural, given such deference, to think that Western notions of belief must be very different from anything familiar in Eastern languages (see my first reference above to Seisuke Hayakawa). But I have been disputing this, and I suppose it takes someone like myself, someone brought up speaking English, to question what Western thinkers mainly say about belief and related notions, to maintain that such thinkers misconceive and mistheorize the nature of their own actual concept of belief. I have argued, against the standard Western view of things, that belief as spoken of in English is necessarily tied to emotion, and it is perhaps easier for a native English speaker to plausibly make this point than for any Chinese philosopher to do so. Incidentally, recent attempts by philosophers like Robert Solomon and Martha Nussbaum to show that emotions are nothing more than rational or irrational beliefs or judgments assume that beliefs themselves don't have to be understood in terms of emotions. If they do, then those attempts get things precisely backward. Finally, the rigid dichotomy Hume makes in the Treatise between emotions/sentiments and cognition/reason falls apart if the latter cannot be separated from the former. Hume was a moral sentimentalist, but I am suggesting that we should all be cognitive sentimentalists and, more generally, philosophical sentimentalists.
} 
need to show that all emotions within a functioning heart-mind have a basic yin-yang structure. But in order now to show this second essential element in my overall argument, I need to talk about how yin and yang are philosophically relevant. I need to show you this, because in fact Chinese and, to my knowledge, Korean and Japanese philosophers have done relatively little philosophically with the notions of yin and yang over the historical millennia and up to the present. Confucius and Mencius don't really bring yin and yang into their ethical thinking and, with certain exceptions during the neo-Confucian period, this has remained true of Chinese philosophy up to the present day. As I said earlier this can be explained in great part by the sheer physicality of the notions of yin and yang as they were applied in ancient China to natural phenomena. But embedded in those notions, as I now aim to show you, is something more purely philosophical that we can use to understand the human psyche. The notions of yin and yang need to be updated, if they are to be relevant to philosophy today, whether Eastern or Western, and historically we have been given at least one clue about how this updating could reasonably and usefully occur.

The notions of yin and yang haven't always been applied exclusively to the purely physical aspects of things. Yes, cold and warm, dark and light, wet and dry are or can seem purely physical, but yin and yang were also originally interpreted as female and male, and the latter concepts aren't purely physical. They apply in virtue of psychological differences and not just physical ones. It seems that Dong Zhongshu, who helped promote Confucianism as the official ideology of the imperial Chinese state, was one of the first, if not the first, to pick up on this feature of one aspect of yin and yang and to run with it. Dong applied yin and yang to ethics in a way that it mainly hadn't been previously, and he did so by contrasting female and male in ethical terms: male yang was characterized by him as benevolent, and female yin as mean-spirited. Well, well, well! That is certainly an ethical application, but it seems to partake of the same meanspiritedness it attributes essentially to women. This shows that mean-spiritedness as a moral property or vice isn't just limited to females, but more importantly and without impugning Dong's thinking any further than I already have, Dong's idea that benevolence is exclusively or essentially the property of men seems wildly out of whack. What about mother love and wifely devotion? But even if Dong was mistaken in particulars, the idea of applying yin and yang in a way that brings in ethically relevant qualities needn't be abandoned altogether. We just have to find a more even-handed way to do that, and I think we can. 
Since ancient times, yin and yang have been associated with ethical qualities beyond those Dong brought into the mix. Yang has been conceived as a kind of active strength and the strength has been understood to encompass more than physical strength and to include some sort of psychological strength. Yin has been variously interpreted in ways that seem ethically relevant but that don't imply bad things about women the way Dong did. When "yin" is translated for the English speaker, three different translations have been prominent. Yin can and has been be equated with passivity, with pliability or pliancy, and with receptivity (all of which take us beyond or away from yin understood in terms of physical properties like wetness and darkness, though I know some want to make connections here as well). But I think there is reason to choose receptivity rather than the other two notions as our way of updating the idea of yin in a philosophically useful way that makes deep connection (in a way that has previously gone unnoticed) with what has been implicit or contained in the idea of yin even as far back as the I Ching. If yin is to do broad and constructive philosophical work, it has to have broader application than the notion of pliancy, and it has to represent a more clearly positive value than either pliancy or passivity represents or exemplifies. By contrast, receptivity not only has clearly positive connotations but also has a very broad application among things that we value. Receptivity to what others are thinking and feeling involves empathizing with them and being open to their opinions even when they initially disagree with one's own. Receptivity also involves openness about one's future. If someone has to plan everything in advance, that is a sign of irrational anxiety about the future, but if one doesn't plan everything and to some extent takes things as they come, one is receptive to what one's future will or may bring one, and this too we regard as something positive. Also, being receptive to the beauty and richness of the world around one rather than having to control or dominate nature is something even we Westerners have come to positively value.

I therefore want to suggest that receptivity may be broad and valuable enough to do the philosophical work that I think the notion of yin can do for us. Yang, then, needs to be understood as basically complementary to yin (though I know there are some traditions in which yin and yang are conceived as opposites, as contrary). ${ }^{4}$ I just mentioned non-physical active

\footnotetext{
${ }^{4}$ In choosing to draw on the tradition of conceiving yin and yang as mutually friendly and complementary, rather than as deeply and in temporally alternating fashion opposed to one
} 
strength as to some extent traditionally associated with the idea of yang, but I would like, again, to use a more general notion to capture or expose a sense of yang broad enough to be complementary to (rather than opposing) broadly conceived yin. Let me suggest that that more general notion is the idea of directed active purpose (which is to be thought of as including but not exhausted by strength of purpose). This idea of yang has its roots in the I Ching as much as yin conceived as receptivity does. And these two broadly focused complementary notions turn out to be involved in all the functioning mind's or xin's emotional states. Let me give you some examples, starting with compassion.

We say many different things about compassion: that it is a feeling, that it is a virtue, that it is a motive, and also, of course, that it is an emotion. Do we have a fourfold ambiguity here? I don't think so, and the ideas of yin and yang updated in the manner suggested just a moment ago can help us to see why. Compassion works via empathy; if someone helps another out of a sheer sense of duty, this isn't compassion but conscientiousness. Compassion requires an emotional connection with the other and a strong

another, I am favoring one traditional "take" on yin-yang over a prominent other. But the proof of the pudding is in the eating. If drawing on the one kind of yin-yang allows us to do significant philosophical work, then that is a reason to rely on it. If the oppositional kind of yin and yang can also help us with contemporary philosophical problems and issues, then certainly it should be brought into the mix. But no one has so far done that; and more importantly, perhaps, there is reason in advance to think oppositional yin and yang can't operate in the broad and deep philosophical terms that the idea of friendly and complementary yin and yang arguably allows for. I conceive yin as receptivity and yang as directed active impulsion/purpose and these are very abstract ideas that it makes sense to imagine as potentially applying to many or all of the different areas philosophy has to deal with. I have already given some arguments to this effect, and further arguments will be given in Chap. 8. But oppositional yin and yang have never been conceptualized in such abstract terms. Yin and yang have been conceived respectively as stillness and motion, as softness and hardness, as femaleness and maleness, as covetousness and benevolence, as acidity and alkalinity, as coldness and warmth, as contraction and expansion, as wetness and dryness, and as darkness and brightness. But these paired notions are so concrete as to make one wonder how they could help us deal with evaluative issues, e.g., in both epistemology and ethics, and that may well then explain why no one has tried to apply oppositional yin and yang in a general way to philosophical issues. However, even if oppositional yin and yang turn out to be able to do significant contemporary philosophical work, that would not undercut what I am saying here and in the book mentioned in footnote 1 about yin and yang. Finally, let me mention that my mutually peaceable yin and yang are not the same as any dialectic of thesis, antithesis, and synthesis. Traditionally, yin and yang were never conceived as stages of a historical noncyclical developing (or progressive) process, and on my view they can both be entirely present at any given time. 
feeling that is comparable to what the other feels. But when one emotionally empathizes with the distress another person feels at the pain, say, in their arm, one doesn't just share their distress, one shares the intentional object of their distress. Consider a father who is empathically infected (as we say) by his daughter's enthusiasm for stamp collecting. What he takes in is not just some unfocused positive feeling, but the daughter's positive feeling as directed toward stamp collecting. If she feels positively about that intentional object, then he begins to feel that way about it too.

Transpose the example to one where what someone takes in empathically is another's distress at the pain they are feeling in their arm. One takes in distress at that pain, not just some overall negative state of displeasure. But think what this means. If a given person is distressed by the pain in their arm, then ex vi terminorum they have some desire, some motivation, to get rid of or alleviate that pain. But in that case, if one empathically takes in the person's distress with the same intentional object that their distress is focused on, then one will feel distress at their pain; and again, ex vi terminorum, one will have some motivation to lessen or terminate that pain, their pain. This is clearly altruistic motivation, and it will lead one to try to help them unless other motives (like sudden danger to oneself from some third party) overwhelm or preempt it.

This picture shows us three of the four sides or aspects of compassion mentioned earlier. When one empathizes with another's distress one feels that distress, just the way Bill Clinton famously claimed to feel other people's pain. So that is compassion considered as a feeling. But it is also compassion considered as an emotion, because distress, whether at one's own pain or at someone else's, is clearly an emotion. We also saw, however, that because of what distress is and what it is to empathize with an emotion as having a given intentional object, the compassionate person will also want to help end or alleviate the other's pain, and that is compassion as a motive. The case mentioned also illustrates compassion as a virtue. When compassion as an emotion-laden empathically derived feeling and compassion as a motive work together in a situation like the one we have described, we have compassion working or acting as a moral virtue. But this still doesn't answer the question whether "compassion" is ambiguous, and we should now turn to that issue.

When someone empathizes with another's distress they are open and receptive to that distress in a rather direct way. Empathy gives us a special form of knowledge by acquaintance of what another is feeling, one that contrasts sharply with the knowledge (by description, in Bertrand Russell's 
sense) that we have or would have if, on the basis of a person's behavior and utterances, we merely hypothesized or inferred that they were in pain. So one element in compassion is a kind of receptivity that makes us immediately acquainted with the inner reality of the other, as when we feel their distress. But one can't have a feeling of distress without having the emotion of distress, and if one doesn't feel the emotion, one clearly isn't feeling the other's distress or being entirely receptive to what they are feeling. In addition, though, and this is the most important point right now, what one is empathically receptive to has to include the intentional object of the other person's feeling(s) or emotion(s). It is the most important point because, as we saw a moment ago, if one is or feels emotionally distressed at the other's emotional distress, one ipso facto has some motivation to do away with or lessen the very pain that the other wants to do away with or lessen. So the full receptivity we are describing here entails and is inseparable from the fact that one is motivated to help the other person in a particular way, and this means that one embodies or exemplifies a kind of directed active purpose in that situation.

Now you may be able to see where I am going. Receptivity is what I am calling yin and directed active purpose or psychological impulse (one is not, for example, asleep) is what I am calling yang, so both yin and yang are exemplified in the situation I have described, the situation where someone has, among other things, the emotion of compassion. Here, therefore, is an emotion that involves both yin and yang, but not just that. Yin and yang are standardly conceived as necessarily complementary to one another (look at the yin-yang symbols illustrated on the Internet), and in the situation just described not only are both yin and yang present, but we have given an argument to show that if the yin of compassionate feeling is there, then the yang of compassionate motivation also has to be there. In other words, and as we have seen, if the situation is one in which one is via empathy fully receptive to what is going on in the other person, then one automatically, necessarily, will have actual specific(ally directed) altruistic motivation/purpose. (This is a point that has been missed by every psychologist I know of who has studied the relationship between empathy and altruism. $)^{5}$ So the situation's yin side, the receptive and feeling side of

\footnotetext{
${ }^{5}$ For an example of a leading psychologist who regards the relationship between empathy and altruism (or compassionate motivation) as purely contingent and merely causal, see Martin Hoffman, Empathy and Moral Development: Implications for Caring and Justice, NY: Cambridge, 2000. No psychologist seems to have recognized the conceptual argument that
} 
compassion, automatically entails the situation's yang side, the fact that it involves a more than purely latent motivation/purpose/impulse directed toward a specific goal. ${ }^{6}$

Furthermore, the yang side of the situation is unthinkable without the yin side. Compassion as a motive represents the directed yang purposive side of compassion, but such a motive cannot exist if one is not being or hasn't been receptive to what the other is feeling. If one isn't thus receptive, then one might feel a conscientious obligation to help the other, but that is not compassion as a motive or a virtue or anything else. Alternatively, if

can be made for seeing empathy as necessarily entailing altruistic motivation, the argument given in the text above. And the same holds true for David Hume. His Treatise of Human Nature is the first place where empathy was ever philosophically described, but the connection Book II draws between (greater) emotional empathy and (greater) altruistic motivation is never said to be conceptual rather than causal. ( $\mathrm{I}$ am indebted here to discussion with Zhang Yan.) For speculative theorizing about how human empathy (as tied to altruism) may have evolved, see my "Empathy as an Instinct" in N. Roughley and T. Schramme, eds., Forms of Fellow Feeling, Cambridge: Cambridge University Press, 2017.

${ }^{6}$ Our yin-yang analysis of compassion (which would also work for benevolence and other moral sentiments) helps us to see how empathy underlies the relevant motivation to help others. Mencius emphasizes compassion (or ren) but doesn't tell us much how about it works because he doesn't relate compassion explicitly to empathy and doesn't see how yin and yang can help explain the workings of empathy and of compassion, etc. I think my updated notions of yin and yang were implicit in traditional Chinese thinking about yin and yang, but I also think philosophers like Mencius may have been distracted from seeing their relevance to moral motivation by the then standard and practically universal use of yin and yang to explain natural and cosmic phenomena. The same goes for Wang Yangming. He draws a tight connection between knowledge and virtue, but he never recognizes how empathy and, more basically, yin and yang might help explain that tight connection, something our text above seeks to demonstrate. Virtues like compassion and virtuous actions like helping to relieve someone's pain distress involve yin and yang in indissoluble unity, but it is also important to note how vicious traits and actions necessarily demonstrate a lack of both yin and yang. Thus the man (say) who commits adultery because unforeseen lust has made him forget his wife and his marriage vows and what they mean in his life and his wife's is (temporarily) both unreceptive (or insensitive) to these facts or factors in his life and derailed from his (I assume) long-term directed purpose of being faithful to his wife and his marriage vows. The adulterous actions thus demonstrate a lack of both yin and yang, and I think it can be argued that the presence or absence of yin-yang criterially distinguishes and explains/justifies the distinction between moral virtue and vice in morally relevant contexts. Note further that although rage, panic, mania, and depression are not necessarily moral vices, they show a lack of rationality. So I want to say that in other-regarding contexts the absence of yin and yang indicates a lack of moral virtue, but that in other contexts that absence is a sign at least of irrationality. Yin and yang can serve as the dividing line between what is good and what is bad in xin (I almost said mind). But much more needs to be said about this. 
one is a psychopath who can't feel what others feel, then if one helps them, it can only be for reasons other than compassion (reasons like self-interest). So the yin and yang sides of compassion arguably depend on each other, and the virtue of compassion can on that basis be said to represent or constitute that necessary codependence. There is no reason, therefore, to say that "compassion" is ambiguous. Rather, we can say that all the different sides of compassion have an equal right to be called compassion because they all entail each other. Compassion is one thing, with different sides that necessarily go together harmoniously, and our use of the term "compassion" to refer freely to all the different sides without our being bothered by worries of ambiguity when we do this, is a kind of implicit recognition that compassion is a single unified phenomenon, one whose parts stand in necessary and inextricable interrelation. But updated yin and yang and yin-yang understood as the indissoluble unity of yin and yang help us see all this about the emotion of compassion. We have our first example, therefore, of an emotion that can be fully understood only in relation to yin and yang as we are understanding them here.

So let's consider another emotion, one not necessarily directed toward other people: namely, fear. Imagine that someone is in a burning building and wants to escape. If the fire represents a danger to them (to their life), then they are likely to feel fear unless the way of escape is a fairly easy one. But let's imagine that it is not. There is only one way out of the building, the fire is strong and coming on fast, and the one and only door that would allow one to escape is difficult to open. Then one is almost certainly going to feel a strong fear of the fire (and a strong desire to get that door opened), and as with compassion I think this emotion of fear necessarily involves an inextricably connected yin side and yang side. The fear is based on (non-empathic) receptivity to what is happening around one, but also involves a desire to do particular things. If one sees the fire coming from a certain direction, one will be motivated to move in a different direction, and if one finds that the only door that would allow escape is hard to open (stuck), one will push extra hard in order to get it open. So one has active motivation that takes one practically in particular directions, but the motivation is responsive to and can change in the light of what one is taking in about one's environment and learning about one's own powers (is one strong enough to push that door open?). We see, therefore, both receptivity and directed active purpose embodied in the fear that arises in this situation, and it is clear that they are inseparable. One won't feel fear unless one is has been and still is receptive to what is going on (yang 
entails yin), and if one isn't motivated or even impelled to do certain things to escape, that will only be because one isn't fully receptive to what is happening around one, to the danger one is in (yin entails yang). For example, if one doesn't act in directed fashion, it could be due to one's having been asleep and being too sleepy still to accurately or attentively monitor or measure what is happening around one. So fear involves yin and yang in inextricable relationship. And as I noted earlier, the situation with the fire also involves a strong desire to escape. One doesn't merely prefer to escape as if one were faced with a choice about which of two beloved flavors of ice cream to buy on a given occasion; rather, one cares about escaping, places great importance on escaping, and such caring, such a desire, can be considered an emotion (it is certainly suffused with emotion). And like the fear, the great emotional concern to escape has a yin side and a yang side that are necessarily connected for the same basic reasons we found this to be true of the fear for one's life that one feels in the situation.

The same thing holds for other desires as well. If one is thirsty and wants to drink, that can only be because one feels thirsty: one's throat, for example, will be dry and one is then monitoring one's body in a way that leads one to want to drink. Thirst, then, is based on a certain cognitive receptivity to one's own bodily states, but then, too, it is constituted by a desire to drink liquid, typically water. If someone is dehydrated but doesn't want to drink, that can only be because they aren't taking in or receiving the usual bodily feelings that instigate a desire to drink. (That may be a sign of an unusual illness, even of rabies.) So the absence of yang desire proves the absence of certain cognitive events and this means, contrapositively, that the cognitive events constituting a receptivity to what is going on in one's body are inextricably tied to thirst and to the desire to drink. But thirst, in its turn, cannot exist without the receptive monitoring of or sensitivity to the bodily signals. One can want to drink for reasons other than thirst, but if it is thirst that leads one to drink or want to drink, that can only be because of the bodily cues or signals one's cognitive receptivity is registering. With thirst, then, yin and yang are necessarily both present and mutually dependent.

Finally, let me mention belief as an example of yin-yang. I said earlier that belief involves epistemically favoring a certain proposition or hypothesis over others inconsistent with it, but it doesn't seem that belief involves anything more than that. If so, then belief is a kind of emotion directed at a particular kind of object on a particular kind of grounds (intellectual or 
evidential ones). So am I prepared to argue that even belief has a yin-yang structure? Yes, I am, and in fact the argument for that conclusion has already, essentially, been given. We have seen that belief cannot be or be considered purely inert or purely intellectual/cognitive if we want to be able to explain the functional role, the usefulness, of beliefs in means-end or instrumental contexts. But belief also involves receptivity, sensitivity, to the world and to one's sensory data, and that is why analytic philosophers often characterize ordinary belief as having a mind-to-world direction of fit. So the belief there is no food in one's house has both a receptive and a directedly purposive or motivated active aspect. It registers what one's senses tell one about one's house and particular objects in it (like cupboards or bread boxes), but it also engages with any desire for food one has in a way that leads/motivates one to act in a particular practical direction (to leave the house). This, again, is yin and yang, and for all the reasons mentioned in connection with our earlier examples, it should be clear too that each of these elements or sides of belief necessitates the other.

So belief can be viewed as a form of emotion, as a cognitive or epistemic emotion, and it is also a yin-yang element or constituent of the functioning heart-mind. Moreover, I think similar reasoning could show you that all the emotions involved in a functioning heart-mind have a yin-yang structure. Of course, this leaves open the possibility that some emotions may not exemplify yin and yang. But that is something the present view shouldn't be at all uncomfortable with. Rage (though not anger as such) and panic (though not fear as such) arguably are or involve non-functional emotions, and I think it can be shown that the non-functionality of rage and panic is due to their exemplifying neither yin nor yang. Rage and panic are non-functional because they leave us unreceptive to what is actually happening around us and unable to act in a concerted, that is, directed way. Exactly what I have just said about rage and panic also holds for depression, and the manic individual not only fails to be yin receptive to what is happening around them and what is actually needed in their particular situation, but acts in a frenzied hyperactive capricious way that lacks the yang of specifically directed persisting purpose. Again, this is psychologically non-functional.

But all of this is entirely consistent with what I am seeking to show here. The idea that we have heart-minds rather than Western-style minds is proved by the fact that all the elements of a functioning mind or psyche necessarily involve emotion, and we have now seen that such emotion by its very nature involves and is constituted by a yin-yang structure. So if our 
philosophical preference for heart-mind over mind is based on the pervasiveness of emotion in our functioning psychology, then it is ultimately based on and more deeply understandable in terms of yin and yang.

That is a surprising result, given the fact that this connection, any strong connection, between heart-mind and yin-yang has never been worked out with any definiteness by Chinese thinkers. ${ }^{7}$ But perhaps despite the lack of precedent, the present arguments will persuade Asian philosophers to rethink or reexamine their ideas about the heart-mind. Heartmind is endogenous to the Far East and so too is yin-yang; so the idea that we can understand ourselves as thinking and feeling creatures on the basis of a distinction or complementarity that is wholly Chinese (no one ever attempts to translate "yin" and "yang" into English) may appeal to our antecedent sense- a sense shared, I hope, among Asian thinkers and also prevalent among some Westerners- that the Chinese and East Asian philosophical traditions have much to teach us today. Most Western philosophers don't yet appreciate that, but I hope that the present argument may help make a difference to that attitude. And even if it doesn't, Chinese and other Asian philosophers ought, I think, to go forward in ways they think of as philosophically illuminating. I hope I have persuaded you here that yin-yang may provide a significant part of the philosophical illumination that the East can bring to the West and to its own philosophical future.

This way of conceiving Chinese thought and its value contrasts starkly with another view of the relationship between Chinese and Western thought that it may at this point be helpful to mention. In an article called "If Philosophy Won't Diversify, Let's Call It What It Is" that appeared on May 11, 2016, in the New York Times philosophy blog "The Stone," Jay Garfield and Bryan Van Norden argued that most philosophy departments in the English-speaking world are invidiously narrow for their lack of attention to philosophical traditions like those of China, India, and so on. This article has been criticized on many sides, but my main criticism arises out of actual agreement with their conclusion about narrowness. Western and especially analytic philosophers believe on the basis of all they have heard about, for example, Chinese philosophy that Chinese thought is either misguided in certain areas or has nothing new to teach them; and if they are right about this, then analytic philosophy can make a strong

${ }^{7}$ For example, what Zhou Dunyi says about the connection between yin-yang and the (ethical) heart-mind in his Taijitu Shuo (Discussion of the Diagram of the Supreme Ultimate/ Polarity) is very vague, not nailed down with any relevant philosophical specificity. 
objection against the conclusion I just said I share with Garfield and Van Norden. What the latter say against present-day analytic philosophy is inadequate because it doesn't directly and philosophically address the issue of whether the West has anything significant to learn, say, from (the philosophical traditions of) China. To really show that the West is overly narrow, one has to argue philosophically for views that are unique to China or India, and so on. Only then and only if such argument is successful or plausible, can one be said to have shown that the West is overly narrow in its philosophy. Sure, we can always have courses on Indian or Chinese thought, but if they have nothing new or valid to teach us, the failure to provide such courses on the part of many or most American philosophy departments is more than somewhat excusable. So Garfield and Van Norden fail to make the point they seek to make in their article, and the same can be said about the book Van Norden subsequently wrote on this same issue.

But then I also want to say that the present chapter does offer the kind of argument I have just called for. It seeks to show that the West has an overly narrow concept of belief and of psychological functioning and that that fact undercuts the validity of Western talk about and conceptualizations of the so-called mind and pure reason. And it also shows us or begins to show us how useful the ideas of yin and yang can be to our philosophical understanding of how our psychology, our psychological functioning, works. If my arguments above are on the right track, then the West needs to wake up to what it can learn from (at least) Chinese thought and culture; and this really does or would establish the point Garfield and Van Norden fail to establish in and through their work, the point (which we all agree on) that Western philosophy is overly narrow (and may continue to be, depending on how open-minded the West can be).

Let me now and finally enlarge our discussion. I have argued that yinyang is the basis of xin functioning, but this says nothing or nothing yet about yin-yang in nature outside or ontologically independent of xin. There is no time for me to go deeply into that issue here, but let me briefly say something à propos about the direction in which my thinking is now going. I believe yin-yang understood as we have understood it here has a role or place within nature outside or as existing independently of xin. For example, when iron is oxidized in the process called rusting, oxygen acts as active yang and the iron as receptive yin, and that is why chemistry speaks of a process of oxidizing or oxidation and not of anything that can be called (the) ironizing or ferrizing (of oxygen). Similar examples can be 
shown to abound in the physical, chemical, and biological realms and can help show-what should be of interest to philosophers and perhaps even to scientists - that yin and yang pervade the natural realm outside of xin. If so, then yin-yang can underlie and pervade the universe generally, and that will be some vindication of traditional Chinese views about these matters.

Western philosophy is historically given to a dilemma between dualism and skepticism. The dualism is part and parcel of the standard Western religious belief that God is totally separate from and wholly other (totaliter aliter) than the world we humans inhabit. ${ }^{8}$ The Western skepticism rejects the religious dualism in favor of a skepticism about human powers to know the world and about (any assurance we might want about) the world's continuing in an orderly and familiar way into its (and our) future. Kant wrote his Critique of Pure Reason to counter such skepticism, though he ended up with a dualism of things in themselves vs. things as they appear to us that is very much analogous to and

${ }^{8}$ Western God-world dualism is closely related to traditional Western mind-body dualism. Both see something-God or the human psyche-as separate or separable from any physical embodiment. Today Western analytic philosophers largely reject mind-body dualism, but they retain belief in a core element of mind-body dualism when they persist in viewing cognition/reason as separable from emotion. Emotion is universally seen as involving the body, so it is no wonder that the Chinese, who see emotion as inseparable from cognition/reason, do not widely accept to mind-body dualism and have never believed in a disembodied personal God (or gods) separate from the world. But by the same token we can see why there has been some tendency in the West to believe in mind-body dualism and God-world dualism, given the rigid separation that has been assumed between cognition/reason and emotion. The persisting belief in the latter has been, so to speak, the sole remnant of the original mindbody and God-world dualisms that once ruled but no longer rule in Western thought. The argument given here in this chapter, if successful, removes this last vestige of those original dualisms. In addition, let me suggest that the dualism Plato posits between the Forms and the material universe is also beholden to the idea of pure reason independent of emotion. There is no reason to posit the Forms in all their purity and otherworldliness unless we are capable of a pure rationality that is capable of knowing them. This doesn't, however, preclude the possibility of forms of predicate abstraction or attribution that are consistent with a thoroughgoing this-worldliness and with the yin-yang necessary conjunction of reason and emotion. Chapter 7 of my recently completed book A Larger Yin-Yang Philosophy: From Mind to Cosmic Harmony (LYYP) describes just such a possibility. I think we can conclude that the examples of both Plato and Kant and perennial Western views about "the mind" show how far astray paradigmatic Western philosophy has gone and, in the light of what I have been saying here and say at greater length in LYYP, indicate how much Western thought needs the correction of Chinese philosophical ideas. 
perhaps ultimately and psychologically derives from the Western religious dualism of God vs. the world.

But there is an alternative to the choice between dualism and skepticism that we can find in traditional Chinese thinking about the cosmos and our place in it. The Chinese have thought that the universe as a whole is harmonious and that our relations with what surrounds us-nature and heaven - are harmonious too. They haven't really argued philosophically for this optimistic view of things, but I have recently been thinking that we can philosophically support belief in such an optimistic harmonious and unified cosmos at least in part via the fact that yin-yang is pervasive of both external nature and xin. There is no time for me to explain further, but if this new direction is plausible and works out, then yin-yang can be used for philosophical purposes that are larger and in some sense more exalted than anything I have suggested in this chapter or will be arguing for later in this book. But making good on that claim is an enterprise for another time and another venue. ${ }^{9}$

\footnotetext{
${ }^{9}$ This material will eventually be published in the just-mentioned book A Larger Yin-Yang Philosophy. I should also explicitly mention that the West's present-day skepticism about our ability to have any assurance about what will happen in the future largely derives from Hume. And now that the argument of this chapter has been given in its entirely, let me return to a question that I think some readers may have been asking and that I earlier put aside in order to get on with the philosophical arguments: the question, namely, of how a Western analytic philosopher came to think yin-yang could give us great help with understanding issues Western philosophy had long been occupied with all on its own. The connection with yin and yang came after I had developed as a moral sentimentalist and as a result of what I eventually came to see was the tight connection between empathy and compassion (or benevolence). I came to understand that that connection was much more conceptual than Hume, recent psychologists working on empathy, and my own earlier self had recognized. Since anyone familiar even at a distance with yin and yang can see that empathy has yin qualities and compassionate motivation yang qualities, once I saw the connection between them as a non-contingent I was struck by the strong resemblance between what I was thinking about empathy and compassion and the traditional Chinese idea that yin and yang are necessarily complementary. Everything I have done with yin and yang since grew out of that initial realization.
} 
Open Access This chapter is licensed under the terms of the Creative Commons Attribution 4.0 International License (http://creativecommons.org/licenses/ by $/ 4.0 /$ ), which permits use, sharing, adaptation, distribution and reproduction in any medium or format, as long as you give appropriate credit to the original author(s) and the source, provide a link to the Creative Commons licence and indicate if changes were made.

The images or other third party material in this chapter are included in the chapter's Creative Commons licence, unless indicated otherwise in a credit line to the material. If material is not included in the chapter's Creative Commons licence and your intended use is not permitted by statutory regulation or exceeds the permitted use, you will need to obtain permission directly from the copyright holder.

(c) (1) 